\title{
Genotype x Environment Interactions Yield Stability of Chrysanthemum (Dendranthema grandiflora Tzvelev.) Genotypes
}

\author{
C.M. Pradeep Kumar*, A.V.D. Dorajeerao, T. Suseela, Zehra Salma and \\ K. Uma Krishna \\ College of Horticulture, Venkataramannagudem, Andhra Pradesh, India \\ *Corresponding author
}

A B S T R A C T

\section{Keywords \\ Chrysanthemum, Yield, Regression coefficient, Environments \\ Article Info \\ Accepted: \\ 26 July 2018 \\ Available Online: \\ 10 August 2018}

The present investigation on stability analysis in chrysanthemum (Dendranthema grandiflora Tzvelev.) was carried out at College of Horticulture, Venkataramannagudem, West Godavari district of Andhra Pradesh during 2017-2018. The genotype x environment ( $\mathrm{G} \times \mathrm{E}$ ) interaction was significant for all the characters except number of flowers per plant. The genotype PusaAditya and Scent Chamanthi showed stability for yield per plot and Scent Chamanthi for yield per hectare with regression coefficient near to unity with non-significant deviation from linearity $\left(\mathrm{S}^{2} \mathrm{~d}_{\mathrm{i}}\right)$ and therefore considered as well adopted to all environments.

\section{Introduction}

The genus Chrysanthemum is widely grown in temperate, tropical and subtropical regions of India. Several species of chrysanthemum are ornamental and are grown in gardens for their beautiful flowers (among different species, the autumn flowering garden chrysanthemum i.e., Dendranthema grandiflorum Tzvelev. is widely grown) and gaining important thought National and International markets. In crop improvement studies, 'stability' reflects the suitability of a variety for general cultivation over a wide range of environments. There are two philosophies of plant breeding in this respect. In the first, characters associated with maximum yield in optimum conditions are different from those associated with survival mechanisms. In the second philosophy, the genotypes with a high yield potential under optimum conditions also express their superiority under limiting conditions. Both the philosophies are ultimately concerned with $\mathrm{G}$ $\times \mathrm{E}$ interaction (Ceccarelli, 1989). However, such inferences need testing across locations. Minimum $\mathrm{G} \times \mathrm{E}$ interactions is desired for a cultivar to be commercially successful, so that it can perform well across the range of environmental conditions in which the cultivar may be grown. Wide adaptation and consistent performance of recommended genotypes is one of the main objectives of any breeding programme (Chaurasia et al., 2005).

Genotype $\mathrm{x}$ environment interactions forced the breeder to choose among the widely 
adaptable cultivars or cultivars adapted to a limited subset of environments. Cultivars showing high yield in a favourable environment are said to have below average stability and cultivars with high yield in an unfavourable environment are said to have above average stability (Jinks and Pooni, 1982). The stability in the productivity and the character of economic importance like yield is of interest to the plant breeder. The desirable genotype may show low genotype $\mathrm{x}$ environment interaction for the agricultural important characters and on the other hand may be more flexible for other characters. Such genotypes are said to be well buffered as those can adjust their genotypic and phenotypic status in response to the changing environmental conditions. This is also called as genetic homeostasis (Lerner, 1954). A genotype which maintains its deviation from the mean yield value when tested at all sites is considered as ecologically stable, or in other words the genotype is considered environmentally stable when a unit change in the genotype performance corresponds to a unit change in environmental index (Mahil et al., 1984).

\section{Materials and Methods}

The points of stability analysis according to Eberhart and Russell (1966) model viz. pooled mean over environments, regression coefficient $\left(b_{\mathrm{i}}\right)$ and deviation from linearity $\left(\mathrm{s}^{2} \mathrm{~d}_{\mathrm{i}}\right)$ are considered as key indices in deciding stability of genotypes. The genotypes with (1) ' $b_{i}$ ' approaching to unity or non-significantly deviating from unity are regarded as generally adaptable with average stability (2) ' $b_{i}$ ' significantly greater than unity are considered as better adaptable to rich or favourable environment, however with below average stability (3) ' $b_{i}$ ' significantly less than unity and/ or having lower magnitude than unity are considered as better adaptable to poor or unfavourable environment with above average stability and (4) The genotypes with significant $\mathrm{S}^{2} \mathrm{~d}_{\mathrm{i}}$ components are considered as highly unpredictable.

\section{Results and Discussion}

The analysis of variance (Table 1) revealed that the genotypes, environments and interaction between the genotype and environment $(\mathrm{G} \times \mathrm{E})$ were significant for all the characters indicating the diversity among the genotypes, environments and $\mathrm{G} \times \mathrm{E}$ studied. A perusal of the results on environmental index for various traits under different environments (Table 2) indicated shade house was observed to be favourable environment for flower yield per plant, flower yield per plot and flower yield per hectare, while polyhouse was observed to be ideal for number of flowers per plant.

\section{Yield parameters}

\section{Number of flowers per plant}

The data (Table 3) revealed that there were significant differences in the number of flowers per plant among the genotypes and environments. The number of flowers per plant was maximum in PusaAditya (279.27) under open field and minimum (23.47) in Star White under the same environment.

This trait was favoured more under the polyhouse $\left(\mathrm{E}_{2}\right)$ since the data were at high magnitude in relation to other environments. The genotype PAU-B-43 recorded the highest number of flowers per plant (239.60) which was on par with PusaAditya (233.53). The lowest number of flowers per plant was noticed in Star White (38.19).

The pooled mean over environments recorded the highest and lowest mean number of flowers per plant with the genotypes PusaAditya (242.25) and Star White (30.91), 
respectively. The genotypes PusaAditya (242.25), Akitha (166.23), PAU-B-43 (201.91) and BC-6-11 (134.43) exhibited significantly higher number of flowers per plant as compared to population mean (131.17).

These genotypes showed significant deviation from linearity and hence could not consider as stable and were unpredictable.

\section{Flower yield per plant $(g)$}

A perusal of data presented in Table 3 revealed that there were significant differences in the flower weight per plant among the genotypes and across the environments. The flower weight per plant was found highest in BC-6-11 with $268 \mathrm{~g}$ in shade house and least in Star White with $156 \mathrm{~g}$ under open field.

The shade house $\left(E_{3}\right)$ appeared to be more favourable for flower weight per plant since the data were at high magnitude as compared to other environments.

The genotype BC-6-11 recorded the highest flower weight per plant with $268 \mathrm{~g}$ which was significantly superior than PusaAditya (240.33 g) whereas the lowest flower weight per plant was noticed in Star White with $195.67 \mathrm{~g}$.

The pooled mean over environments documented the maximum flower weight per plant with the genotypes BC-6-11 (244.44) and minimum with Star White (175.44). The genotypes BC-6-11 (244.44), PusaAditya (234.33), Scent Chamanthi (220.11) and Akitha (226) exhibited significantly highest flower weight per plant as compared to population mean (209.59).

The genotype $\mathrm{x}$ environment interaction was not significant for flower weight per plant showed in (Table 1). Similar non-significant interaction due to $\mathrm{G} \times \mathrm{E}$ was found for flower yield per plant in earlier studies made by Priyanka (2012) in chrysanthemum.

\section{Flower yield per plot $(\mathrm{kg})$}

A perusal of data (Table 4) and (Fig. 1) revealed that there were significant differences in the yield per plot among the genotypes and across the environments. Maximum yield per plot was recorded by the genotype BC-6-11 in shade house $(8.05 \mathrm{~kg})$ and minimum $(4.68 \mathrm{~kg})$ in Star White under open field.

The shade house $\left(\mathrm{E}_{3}\right)$ was observed to possess relatively higher value for yield per plot among the environments. The genotype BC-611 recorded the more yield per plot with 8.05 $\mathrm{kg}$ which was statistically superior to PusaAditya $(7.22 \mathrm{~kg})$. The lowest yield per plot was noticed in Star White $(5.88 \mathrm{~kg})$.

The pooled mean over environments for flower yield per plot was found to be the highest in the genotype BC-6-11 (7.34 kg) and the least yield per plot was noticed with Star White $(5.27 \mathrm{~kg})$. The genotype PusaAditya (7.04 kg), Akitha (6.79 kg), Scent Chamanthi $(6.62 \mathrm{~kg})$ and BC-6-11(7.34 kg) exhibited significantly greater yield as compared to population mean $(6.30 \mathrm{~kg})$.

PusaAditya and Scent Chamanthi genotypes had regression coefficients near to unity with non-significant deviation from linearity $\left(\mathrm{S}^{2} \mathrm{~d}_{\mathrm{i}}\right)$ and therefore these could be considered as well adaptable to different environments with average stability. Similar result found by Sreenivas (2015) in okra.

The BC-6-11 genotype has ' $b_{i}$ ' significantly greater than unity, therefore considered as better adaptable to rich environment, however with below average stability and Akitha genotype has ' $b_{i}$ ' significantly less than unity are considered as better adaptable to poor environment with above average stability. 
Table.1 Analysis of variance (pooled) for stability parameters (mean sum of squares) in chrysanthemum (Dendranthema grandiflora Tzvelev.) for yield

\begin{tabular}{|c|c|c|c|c|c|c|c|c|}
\hline S. No. & Parameters & Genotypes (g) & Environment (E) & Gen.xEnv. & E (linear) & G x E (linear) & Pooled deviation & Pooled error \\
\hline 1 & Number of flowers per plant & $10,621.69^{* *}$ & 224.270 & $996.583 * *$ & 448.540 & $1,729.725 * *$ & $237.098^{* *}$ & 167.789 \\
\hline 2 & Flowers yield per plant(g) & $1,482.091 * *$ & $1,040.726^{* *}$ & 122.314 & $2,081.452 * *$ & 145.839 & $88.911 * *$ & 58.483 \\
\hline 3 & Flower yield per plot (kg) & $2.174 * *$ & $1.260 *$ & $0.274^{* *}$ & $2.519 * *$ & $0.487^{* *}$ & $0.055^{* *}$ & 0.056 \\
\hline 4 & Flower yield per hectare $\left(t^{-1} h a\right)$ & $12.107 * *$ & $12.003^{*}$ & $1.873^{*}$ & $24.007 * *$ & $3.145^{* *}$ & $0.541^{*}$ & 0.617 \\
\hline
\end{tabular}
*, ** Significant at $5 \%$ and $1 \%$ levels respectively

Table.2 Environmental indices for flowering, yield and quality in chrysanthemum (Dendranthema grandiflora Tzvelev.)

\begin{tabular}{|c|l|c|c|c|}
\hline \multicolumn{1}{|c|}{ S. No. } & \multicolumn{1}{|c|}{ Parameters } & Open Field $\left(\mathbb{E}_{1}\right)$ & Polyhouse $\left(\mathbb{E}_{2}\right)$ \\
\hline $\mathbf{1}$ & Number of flowers per plant & -5.21 & 4.40 \\
\hline $\mathbf{2}$ & Flower yield per plant $(\mathrm{g})$ & -6.96 & -4.76 \\
\hline $\mathbf{3}$ & Flower yield per plot $(\mathrm{kg})$ & -0.21 & -0.14 & 1.17 \\
\hline $\mathbf{4}$ & Flower yield per hectare $\left(\mathrm{t}^{-1}\right.$ ha) & -0.97 & -0.22 & 0.35 \\
\hline
\end{tabular}

Table.3 Stability parameters for No. of flowers per plant in number and gram of chrysanthemum genotypes

\begin{tabular}{|c|c|c|c|c|c|c|c|c|c|c|c|c|}
\hline \multirow[b]{3}{*}{ Genotypes } & \multicolumn{6}{|c|}{ No. of flowers per plant } & \multicolumn{6}{|c|}{ Flower yield per plant (g) } \\
\hline & \multicolumn{4}{|c|}{ Environments } & \multirow[t]{2}{*}{$\mathbf{b}_{\mathbf{i}}$} & \multirow[t]{2}{*}{$\mathbf{S}^{2} \mathbf{d}_{\mathrm{i}}$} & \multicolumn{4}{|c|}{ Environments } & \multirow[t]{2}{*}{$\mathbf{b}_{\mathbf{i}}$} & \multirow[t]{2}{*}{$\mathbf{S}^{2} \mathbf{d}_{\mathrm{i}}$} \\
\hline & $\mathbf{E}_{1}$ & $\mathbf{E}_{2}$ & $\mathbf{E}_{3}$ & $\begin{array}{l}\text { Pooled } \\
\text { Mean }\end{array}$ & & & $\mathbf{E}_{1}$ & $\mathbf{E}_{2}$ & $\mathbf{E}_{3}$ & $\begin{array}{c}\text { Pooled } \\
\text { Mean }\end{array}$ & & \\
\hline Mother Theresa(V1) & 67.27 & 131.90 & 100.54 & 99.90 & $6.690 * *$ & $25.969 * *$ & 158.33 & 206.00 & 183.67 & 182.67 & 2.103 & $197.406^{* * *}$ \\
\hline PusaAditya(V2) & 279.27 & 233.53 & 213.94 & 242.25 & $-5.828 * *$ & $668.447 * *$ & 230.67 & 240.33 & 232.00 & 234.33 & 0.513 & $-19.473 * *$ \\
\hline Reagun Emperor(V3) & 96.03 & 150.91 & 122.80 & 123.25 & $5.641^{*}$ & $22.623 * *$ & 201.67 & 214.67 & 199.67 & 205.33 & 0.777 & $-12.532 * *$ \\
\hline Akitha (V4) & 211.32 & 110.09 & 177.27 & 166.23 & $-10.006 * *$ & $760.644 * *$ & 238.00 & 221.00 & 219.00 & 226.00 & $-0.522 * *$ & $141.704 * *$ \\
\hline PAU-B-107(V5) & 97.06 & 94.46 & 110.21 & 100.58 & 0.110 & $86.109^{* *}$ & 197.67 & 219.33 & 206.67 & 207.89 & 1.013 & 3.695 \\
\hline Red Gold(V6) & 110.10 & 100.30 & 105.78 & 105.39 & -0.996 & $-52.131 * *$ & 209.67 & 217.67 & 197.00 & 208.11 & 0.740 & $83.861 * *$ \\
\hline PAU-B-43(V7) & 136.05 & 239.60 & 230.08 & 201.91 & $11.783 * *$ & $267.483 * *$ & 175.67 & 206.67 & 192.33 & 191.56 & 1.363 & $75.000 * *$ \\
\hline Scent chamanthi(V8) & 114.55 & 111.31 & 94.76 & 106.88 & -0.810 & $140.019 * *$ & 227.33 & 223.67 & 209.33 & 220.11 & 0.205 & $152.726^{* *}$ \\
\hline Star White (V9) & 23.47 & 38.19 & 31.07 & 30.91 & 1.523 & $-51.750 * *$ & 156.00 & 195.67 & 174.67 & 175.44 & 1.805 & $89.747 * *$ \\
\hline BC-6-11(V10) & 124.46 & 141.83 & 137.01 & 134.43 & 1.892 & $-55.733 * *$ & 231.33 & 268.00 & 234.00 & 244.44 & 2.002 & $-17.966 * *$ \\
\hline General mean & 125.96 & 135.21 & 132.35 & 131.17 & & & 202.63 & 221.30 & 204.83 & 209.59 & & \\
\hline $\mathrm{SE}(\mathbf{m})$ & 3.67 & 11.24 & 5.28 & 10.89 & & & 3.46 & 4.21 & 5.41 & 6.67 & & \\
\hline CD@ $9 \%$ & 10.91 & 33.40 & 15.68 & 30.79 & & & 10.25 & 12.45 & 16.00 & 18.66 & & \\
\hline
\end{tabular}

*,**, Significant at $5 \%$ and $1 \%$ level respectively, $\mathrm{E}_{1}$ - Open Field, $\mathrm{E}_{2}$ - Polyhouse, $\mathrm{E}_{3}$ - Shadehouse, $\mathrm{b}_{\mathrm{i}}-$ Regression coefficient,

$\mathrm{S}^{2} \mathrm{~d}_{\mathrm{i}}-$ Mean square deviation, CD- Critical Difference 
Table.4 Stability parameters for Yield per plot and yield per hectare in chrysanthemum genotypes

\begin{tabular}{|c|c|c|c|c|c|c|c|c|c|c|c|c|}
\hline \multirow{3}{*}{ Genotypes } & \multicolumn{6}{|c|}{ Yield per plot (kg) } & \multicolumn{6}{|c|}{ Yield per hectare $\left(\mathrm{t} \mathrm{ha}^{-1}\right)$} \\
\hline & \multicolumn{4}{|c|}{ Environments } & \multirow{2}{*}{$\mathbf{b}_{\mathbf{i}}$} & \multirow{2}{*}{$\mathbf{S}^{2} \mathbf{d}_{\mathbf{i}}$} & \multicolumn{4}{|c|}{ Environments } & \multirow{2}{*}{$\mathbf{b}_{\mathbf{i}}$} & \multirow{2}{*}{$S^{2} d$} \\
\hline & $\mathbf{E}_{1}$ & $\mathbf{E}_{2}$ & $\mathbf{E}_{\mathbf{3}}$ & $\begin{array}{c}\text { Pooled } \\
\text { Mean }\end{array}$ & & & $\mathbf{E}_{1}$ & $\mathbf{E}_{2}$ & $\mathbf{E}_{\mathbf{3}}$ & $\begin{array}{l}\text { Pooled } \\
\text { Mean }\end{array}$ & & \\
\hline $\begin{array}{l}\text { Mother } \\
\text { Theresa(V1) }\end{array}$ & 4.75 & 5.52 & 6.18 & 5.48 & $2.106^{* *}$ & 0.056 & 12.57 & 14.59 & 16.36 & 14.51 & 1.691 & 0.133 \\
\hline PusaAditya(V2) & 6.93 & 6.98 & 7.22 & 7.04 & 0.499 & 0.006 & 18.34 & 18.47 & 19.09 & 18.63 & 0.360 & -0.195 \\
\hline $\begin{array}{l}\text { Reagun } \\
\text { Emperor(V3) } \\
\end{array}$ & 6.05 & 6.00 & 6.45 & 6.17 & 0.792 & 0.002 & 16.01 & 15.87 & 17.07 & 16.32 & 0.538 & -0.039 \\
\hline Akitha (V4) & 7.15 & 6.58 & 6.65 & 6.79 & $-0.506^{* *}$ & -0.016 & 18.92 & 17.42 & 17.59 & 17.97 & $-0.516^{* *}$ & 0.506 \\
\hline PAU-B-107(V5) & 5.98 & 6.20 & 6.58 & 6.25 & 0.966 & -0.014 & 15.81 & 16.41 & 17.42 & 16.55 & 0.740 & -0.204 \\
\hline Red Gold(V6) & 6.30 & 5.92 & 6.54 & 6.25 & 0.735 & 0.093 & 16.27 & 15.66 & 17.29 & 16.41 & 0.565 & 0.389 \\
\hline$\overline{\text { PAU-B-43(V7) }}$ & 5.28 & 5.78 & 6.22 & 5.76 & 1.371 & 0.156 & 13.98 & 15.30 & 16.45 & 15.24 & 1.101 & -0.062 \\
\hline $\begin{array}{l}\text { Scent } \\
\text { chamanthi(V8) }\end{array}$ & 6.83 & 6.30 & 6.73 & 6.62 & 0.214 & 0.045 & 18.04 & 16.67 & 17.80 & 17.50 & $0.010^{*}$ & 0.877 \\
\hline Star White (V9) & 4.68 & 5.25 & 5.88 & 5.27 & 1.821 & -0.002 & 10.87 & 13.89 & 15.56 & 13.44 & $2.047^{*}$ & 1.077 \\
\hline BC-6-11(V10) & 6.95 & 7.03 & 8.05 & 7.34 & $2.002 *$ & 0.033 & 16.34 & 20.29 & 24.07 & 20.23 & $3.464 * *$ & 0.871 \\
\hline General mean & 6.09 & 6.16 & 6.65 & 6.30 & & & 16.11 & 16.29 & 17.59 & 16.66 & & \\
\hline $\mathbf{S E}(\mathbf{m})$ & 0.12 & 0.16 & 0.13 & 0.17 & & & 0.51 & 0.48 & 4.60 & 0.52 & & \\
\hline CD@ 5\% & 0.35 & 0.48 & 0.37 & 0.48 & & & 1.53 & 1.44 & 13.63 & 1.47 & & \\
\hline
\end{tabular}

$*$,**, Significant at $5 \%$ and $1 \%$ level respectively, $\mathrm{E}_{1}$ - Open Field, $\mathrm{E}_{2}$ - Polyhouse, $\mathrm{E}_{3}$ - Shadehouse, $\mathrm{b}_{\mathrm{i}}-$ Regression coefficient, $\mathrm{S}^{2} \mathrm{~d}_{\mathrm{i}}-$ Mean square deviation, CD- Critical Difference 
Fig.1 Performance vs. stability of genotype for yield per plot in chrysanthemum

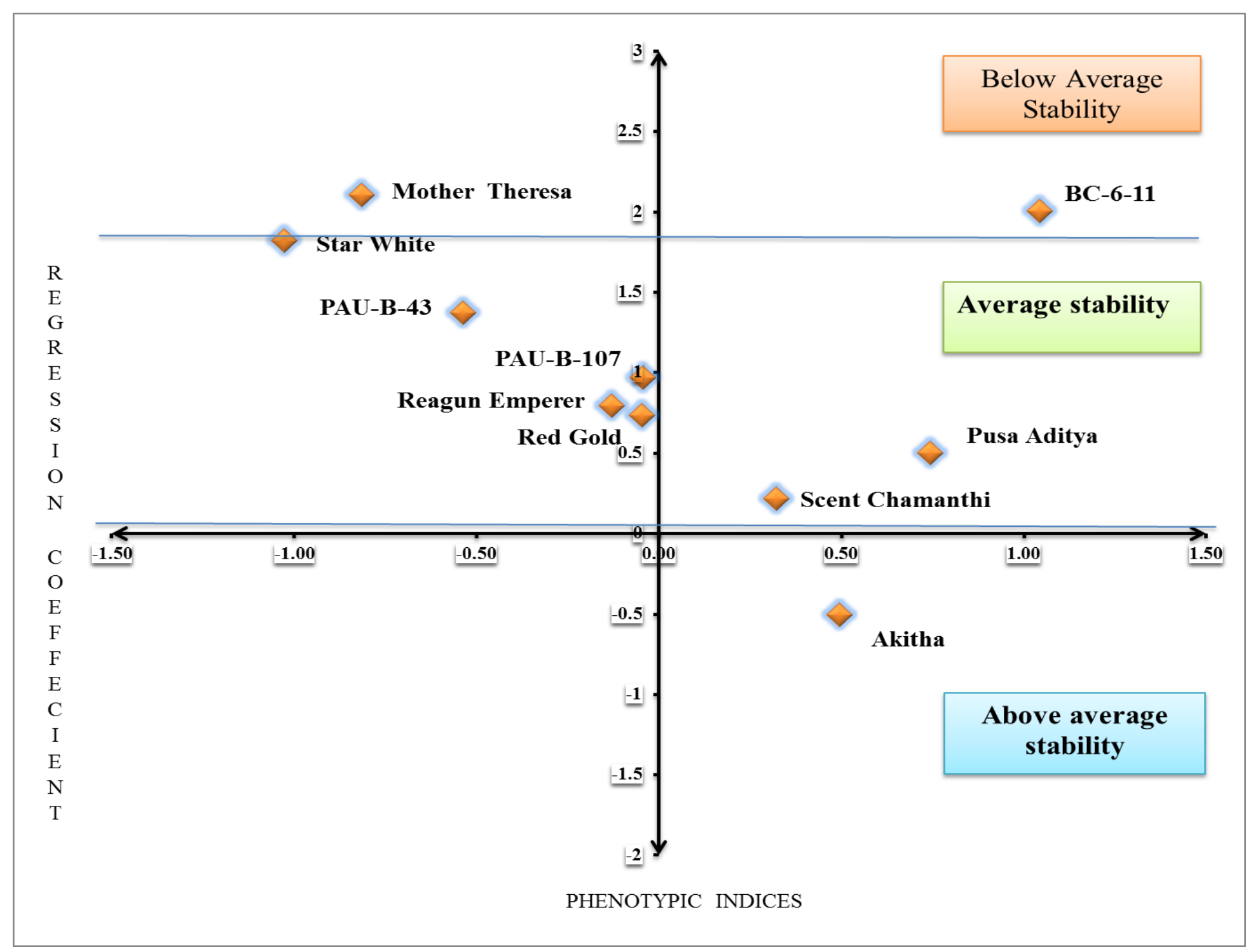


Fig.2 Performance $v s$. stability of genotype for yield per hectare in chrysanthemum

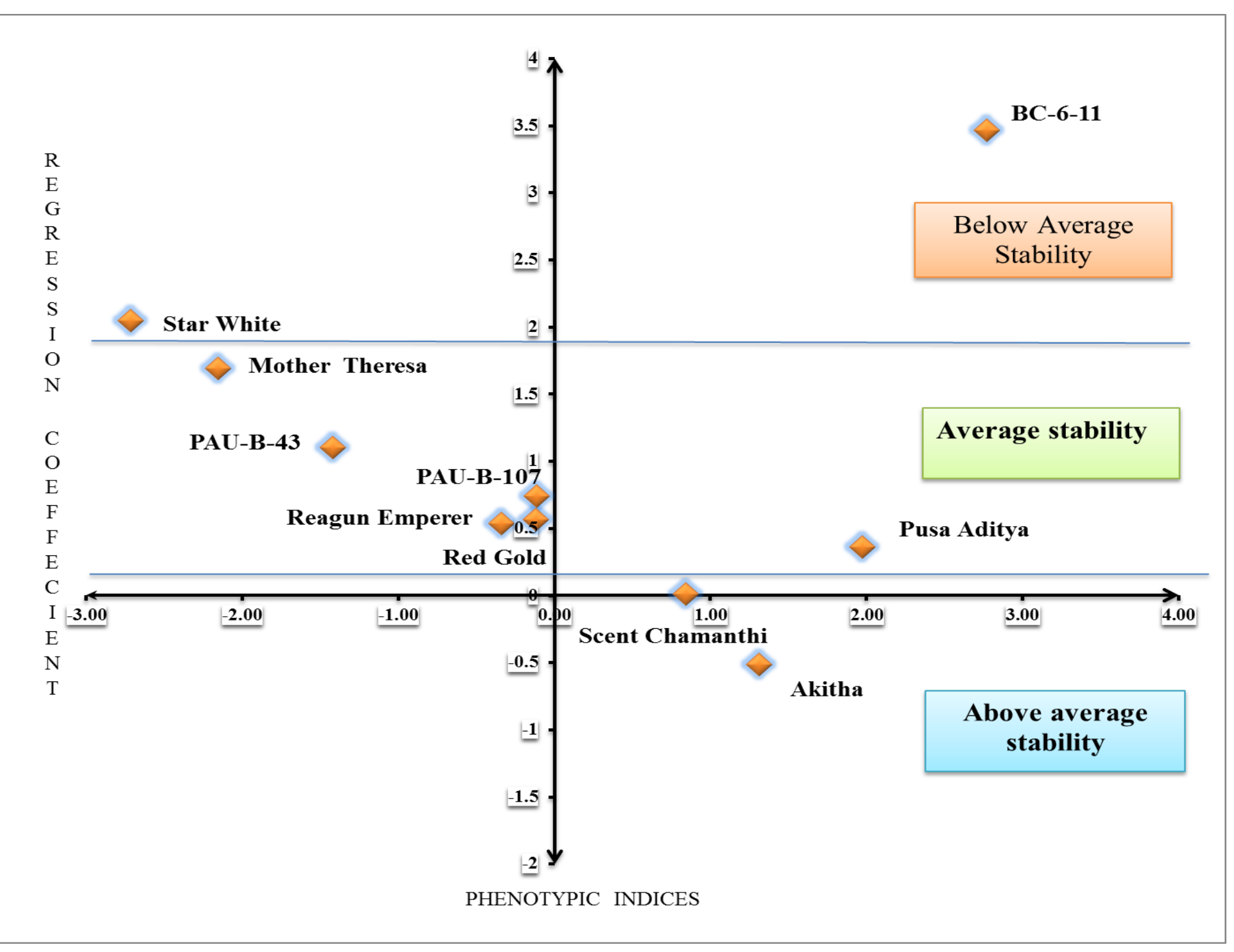


It is worthy to mention here that the genotype Mother Theresa failed to exhibit better performance above population mean even though it recorded $b_{i}$ value significantly greater than one with a non-significant deviation and hence could not be a superior genotype.

\section{Flower yield per hectare (t)}

Significant variations were noted (Table 4 and Fig. 2) in the yield per hectare among the genotypes and environments. The yield per hectare was found highest in BC-6-11 with $24.07 \mathrm{t} \mathrm{ha}^{-1}$ under shade house and lowest in Star White (10.87 $\left.\mathrm{t} \mathrm{ha}^{-1}\right)$ under open field.

The shade house $\left(\mathrm{E}_{3}\right)$ was found to be more favourable for yield per hectare since the data were at high magnitude compared to other two environments. The genotype BC-6-11 recorded more yield per hectare $\left(24.07 \mathrm{t} \mathrm{ha}^{-1}\right)$. The genotype BC-6-11 was statistically on par with PusaAditya (19.09 $\left.\mathrm{t} \mathrm{ha}^{-1}\right)$, Scent Chamanthi (17.80 $\left.\mathrm{t} \mathrm{ha}^{-1}\right)$, Akitha (17.59 $\mathrm{t} \mathrm{ha}^{-}$ $\left.{ }^{1}\right)$, PAU-B-107(17.42 $\left.\mathrm{t} \mathrm{ha}^{-1}\right)$, Red Gold (17.29 $\left.\mathrm{t} \mathrm{ha}^{-1}\right)$, Reagun Emperor $\left(17.07 \mathrm{t} \mathrm{ha}^{-1}\right)$, PAUB-43 (16.45 $\left.\mathrm{t} \mathrm{ha}^{-1}\right)$, Mother Theresa (16.36 t $\left.\mathrm{ha}^{-1}\right)$ and Star White $\left(15.56 \mathrm{t} \mathrm{ha}^{-1}\right)$. The genotype Star White $\left(15.56 \mathrm{t} \mathrm{ha}^{-1}\right)$ recorded the lowest yield per hectare.

The pooled mean over environments with respect to the yield per hectare was ranging between $13.44 \mathrm{t} \mathrm{ha}^{-1}$ and $20.23 \mathrm{t} \mathrm{ha}^{-1}$ in BC-611. The genotype PusaAditya (18.63 $\left.\mathrm{t} \mathrm{ha}^{-1}\right)$, Akitha (17.97 $\left.\mathrm{t} \mathrm{ha}^{-1}\right)$, Scent Chamanthi (17.50 $\left.\mathrm{t} \mathrm{ha}^{-1}\right)$ and BC-6-11 (20.23 $\left.\mathrm{t} \mathrm{ha}^{-1}\right)$ exhibited significantly higher yield per hectare as compared to population mean $\left(16.66 \mathrm{t} \mathrm{ha}^{-1}\right)$.

PusaAditya genotype had regression coefficient near to unity with non-significant deviation from linearity $\left(S^{2} d_{i}\right)$. It designates that the genotype was well adaptable to different environments with average stability.
Similar result was found on stability of yield per hectare by Hemalanaik (2003) in marigold and Sreenivasulu (2004) in China aster.

The BC-6-11 genotype has ' $b_{i}$ ' significantly greater than unity and hence considered as better adaptable to rich environment, however with below average stability and genotype like Akitha and Scent Chamanthihad ' $b_{i}$ ' significantly less than unity are considered as better adaptable to poor environment with above average stability.

\section{References}

Ceccarelli, S. 1989. Wide adaptation: How wide? Euphytica, 40: 197 - 205.

Chaurasia, S. N. S, Singh, M. and Mathura Rai. 2005. Stability analysis for growth and yield attributes in brinjal. Vegetable Science. 32(2): 120 - 22.

Eberhart, S. A. and Russell, W. A. 1966.Stability parameters for comparing varieties. Crop Science. 6: 36 - 40.

Hemalanaik, B. 2003. Stability analysis and standardization of production technology for flower and xanthophylls yield in marigold (Tagetes spp.) Ph. D. Thesis, University of Agricultural Science, Dharwad.

Jinks, J. L. and Pooni, H. S. 1982. Determination of the environmental sensitivity of selection lines of Nicotianarustica by the selection of environments. Herdity. 49: $291-294$.

Lerner, I.M. 1954. Genetic Homeostasis. Oliver and Boyd. London. Edinburg.

Mahil, J. F. Jenkins, J. N, McCarty Jr-1 and Parrott, W.L. 1984. Performance and stability of double haploid lines of upland cotton derived via semigenny. Crop Science.24: 271 - 77.

Priyanka, B. M. 2012. Genotypic stability analysis in chrysanthemum (Dendranthema grandiflorum Tzvel.). 
M.Sc. (Hort.) thesis. University of Horticultural Sciences, Bagalkot.

Sreenivas, G. 2015. Stability analysis and molecular characterization of $\mathrm{F}_{1}$ hybrids in okra (Abelmoschus esculentus L. Moench). M.Sc. (Hort.) Thesis. Kerala
Agriculture

University, Thiruvananthapuram.

Sreenivasulu, G. B. 2004. Stability analysis in China aster (Callistephus chinensis (L.) Nees.) varieties. M.Sc. (Hort.) thesis. University of Horticultural Sciences, Bagalkot.

\section{How to cite this article:}

Pradeep Kumar, C.M., A.V.D. Dorajeerao, T. Suseela, Zehra Salma and Uma Krishna, K. 2018. Genotype x Environment Interactions Yield Stability of Chrysanthemum (Dendranthema grandiflora Tzvelev.) Genotypes. Int.J.Curr.Microbiol.App.Sci. 7(08): 4396-4404.

doi: https://doi.org/10.20546/ijcmas.2018.708.462 